\title{
Health Effects of Toxic Organic Compounds from Coal- The Case of Balkan Endemic Nephropathy (BEN)
}

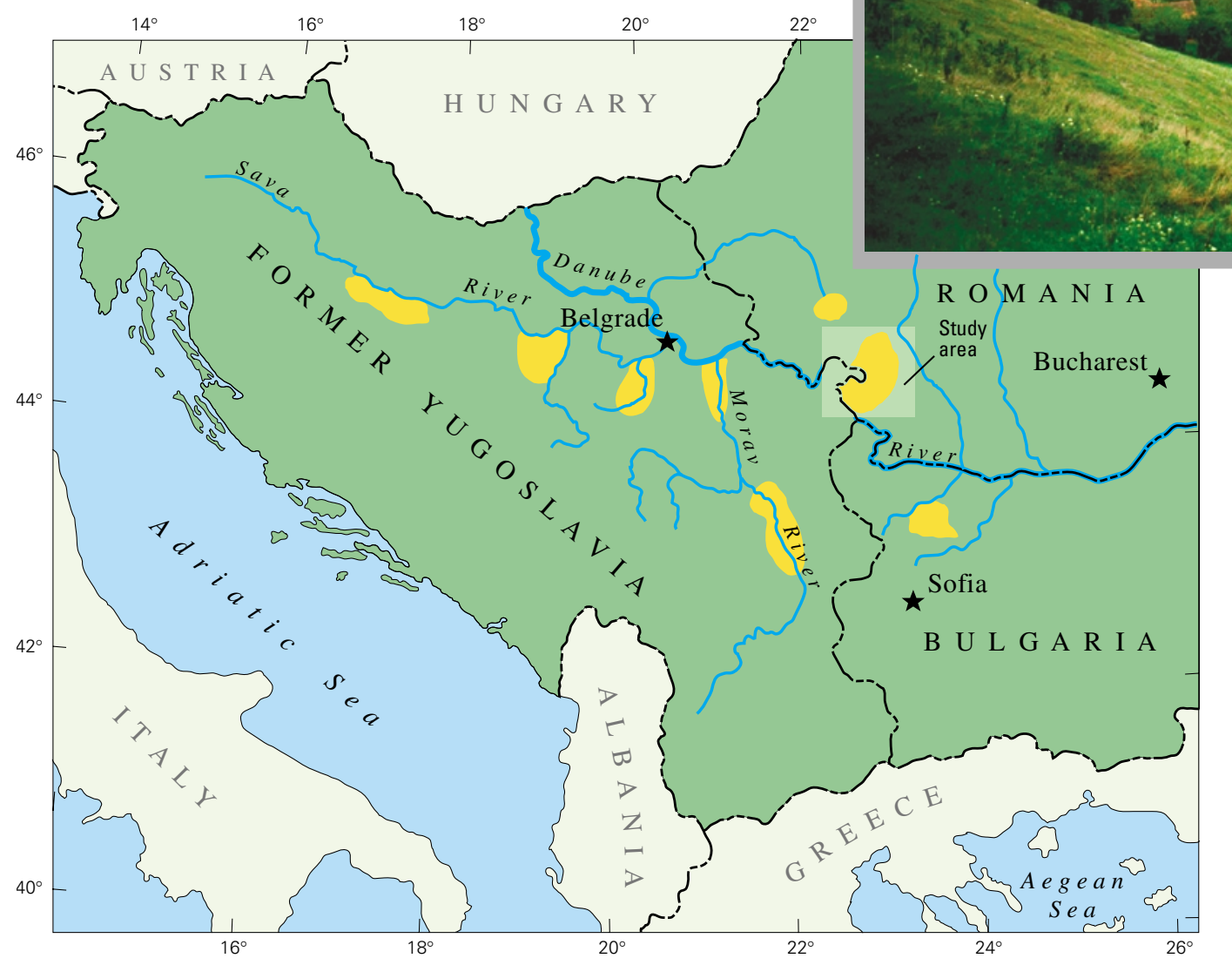

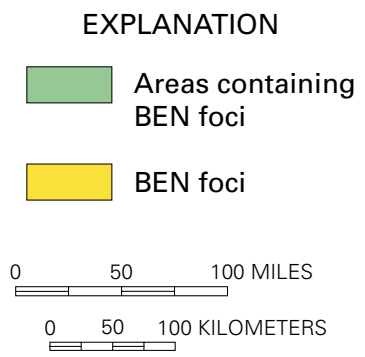

Figure 1. Map showing the distribution of the BEN foci in the Balkan Peninsula. The inset shows a typical panorama of a village in Romania with a BEN-afflicted population. Most of the affected villages are in valley bottoms along streams flowing into the Danube River.

\section{Introduction}

Balkan endemic nephropathy (BEN) is a serious kidney disease (see sidebar) that occurs only in clusters of rural villages located in tributary valleys of the Danube River in the Balkan Peninsula (Hall, 1992). Figure 1 shows the areas in the former Yugoslavia (Serbia, Croatia, Bosnia, and Kosovo), Romania, and Bulgaria affected by BEN. It is believed that at least 25,000 persons are suffering from BEN or are suspected of having the disease and that the total number of people at risk may exceed 100,000. BEN was first described as a distinct medical entity in 1956, but it may have existed unde- scribed for many centuries. The geographic distribution of the disease has not changed significantly since the 1950's. Villages afflicted in the past continue to have cases of BEN, while villages with no history of BEN (some of which are only a few miles from affected villages) have remained free of this disease.

The mysterious nature of BEN has led people in the affected villages to link the disease to incomprehensible cosmic powers, and some villagers wear amulets, use pendants, perform ritual prayers, or move from the area to be spared from the disease. Because BEN is confined to restricted areas of the
Balkans, many scientists speculate that it may be caused by exposure of the rural residents to some unknown toxic substance(s) in the environment, possibly coupled with a genetic predisposition. Despite significant research into BEN, its causes remain unknown.

Work by the U.S. Geological Survey (USGS) and others in the early 1990's noted the close correspondence between the location of the affected villages and the occurrence of coal deposits, specifically lignites deposited in the Pliocene Epoch 5.3 million to 1.6 million years ago (Feder and others, 1991). Further research showed that the well water in affected villages has measurable amounts 
of organic compounds such as polycyclic aromatic hydrocarbons (PAH's) and aromatic amines that may be toxic. The nearby Pliocene lignite deposits are unusual in that these coals release large amounts of organic substances when leached with water or other polar solvents. These coal deposits, therefore, could be a source of toxic organic compounds such as those found in the well water from the affected villages. Consumption of well water contaminated with toxic organic compounds derived from the coal may be implicated in the onset of BEN.

\section{The Pliocene Lignite Hypothesis}

On the basis of these preliminary findings, USGS scientists developed the Pliocene lignite hypothesis to explain the occurrence and distribution of BEN (Feder and others, 1991; Orem and others, 1999). This hypothesis proposes that ground water leaches toxic organic compounds from the Pliocene lignite deposits in the steep hills surrounding the affected villages (fig. 2). The toxic organic compounds are then transported in the ground water to wells in the affected villages, which lie in narrow alluvial valleys (fig. 1 inset). People in the affected villages use the well water (fig. 3) for drinking and cooking. Over time, the toxic organic compounds in the water may cause progressive kidney damage or accumulate in the kidney tissue, resulting in the onset of BEN, usually by age 40 to 60 (fig. 4). Toxic organic compounds in the well water originating from the Pliocene lignites may also be implicated in the unusually high incidence of upper urinary tract cancers in individuals with BEN.

Work currently underway to provide further evidence to support this hypothesis is jointly funded by the USGS (Energy Resources Program), the North Atlantic Treaty Organization (NATO), and the Romanian Ministry of Health. This work is focusing on the affected areas in southwestern Romania (study area shown in fig. 1), and scientists from the USGS and the Romanian Ministry of Health are sampling water supplies (wells and springs) and coal mines and are conducting interviews with villagers in the affected area. This work will be expanded into Bulgaria in 2001 and into other countries affected by BEN in future years.

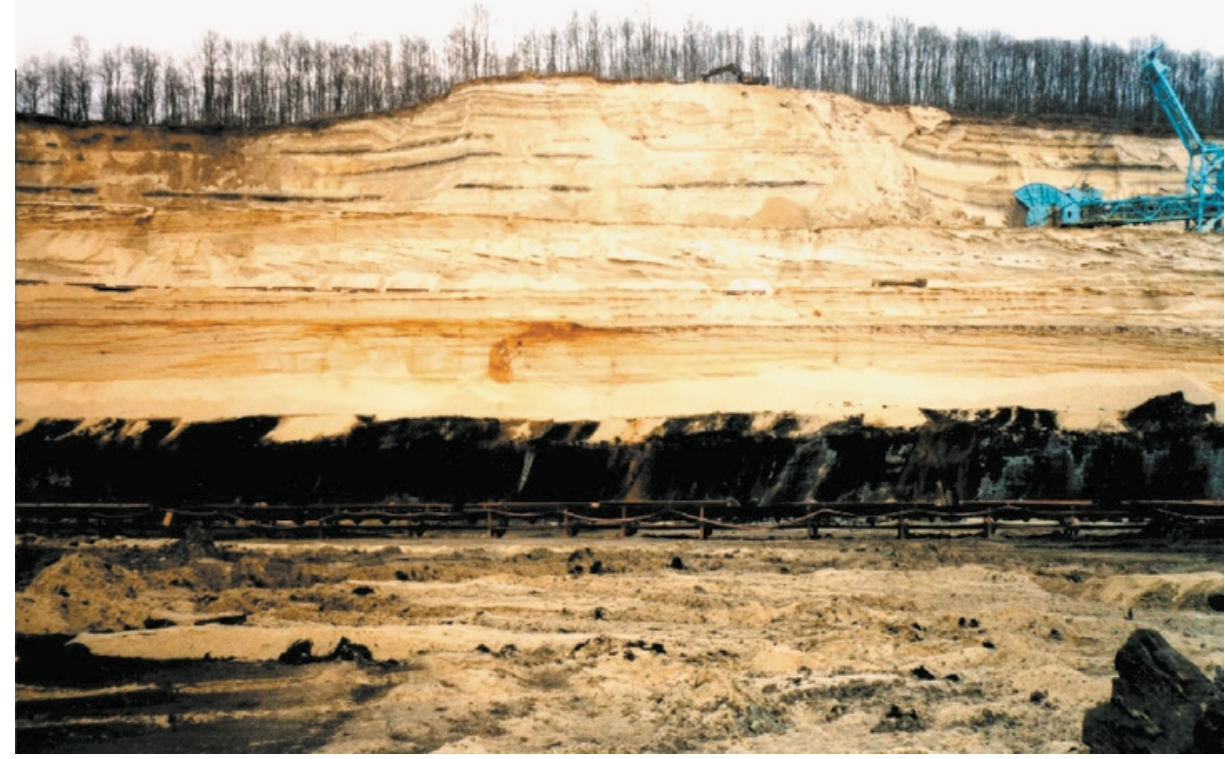

Figure 2. Opencast coal (Pliocene lignite) mine located in the main Romanian BEN-affected area. Most visible is coal layer \#IV (dark brown, 25 feet thick), which underlies the entire affected area.

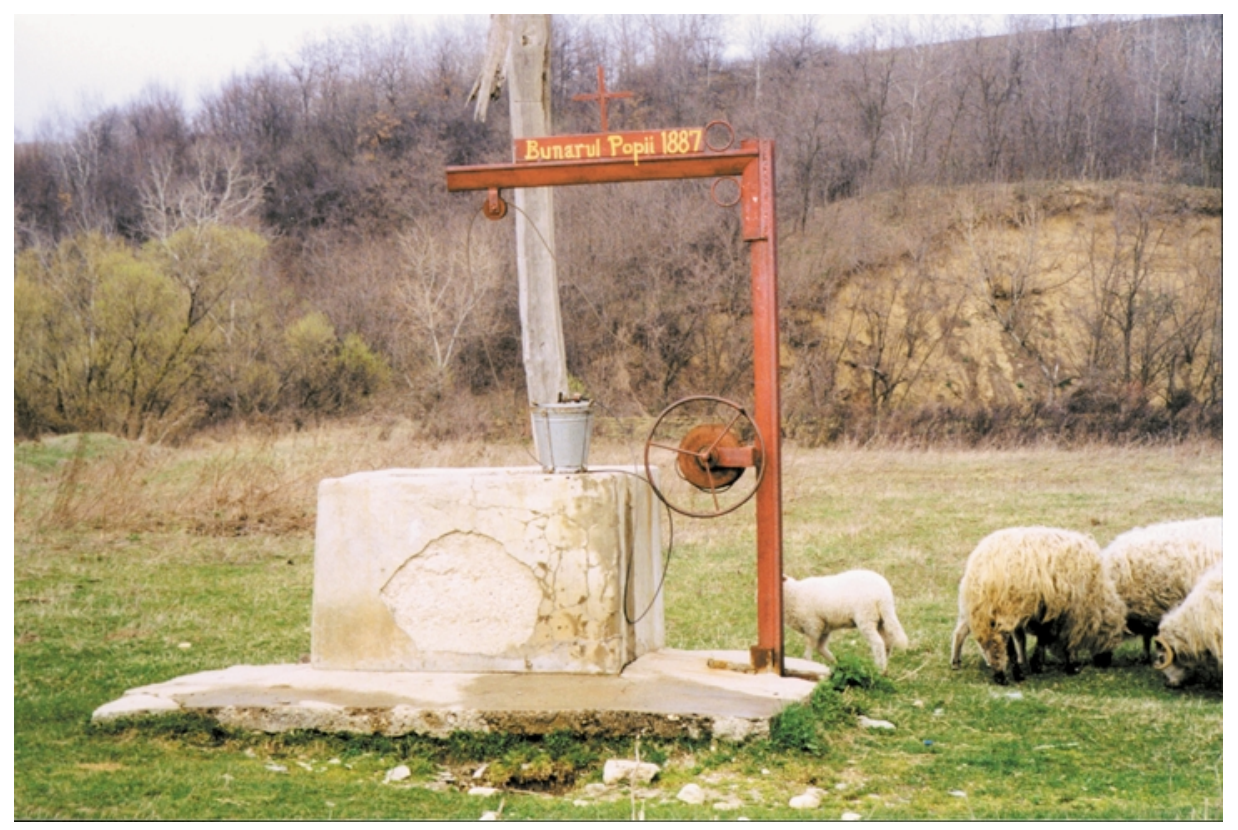

Figure 3. Shallow water well typical of those used by the villagers in the BEN-affected area in the Balkan Peninsula.

\section{Lignite History and Composition}

Macroscopically, the Pliocene lignites from the BEN-affected areas are composed primarily of fossil wood; chemically, the lignites are very similar to the plant material and peat from which they formed (Orem and others, 1999). The ancient peat deposits that formed the Romanian Pliocene lignites were laid down about 5 million-3 million years ago in subtropical swamp forests where rivers entered an ancient sea in the
Dacian Basin, which occupied the site of present-day Romania. Vegetation in these ancient swamps included cypress and sequoia trees, as well as smaller swamp plants. The lignites that formed during millions of years following burial of these ancient peats are rich in water-soluble organic substances. Similar coal depositional environments existed during the Tertiary (from 66.4 million to 1.6 million years ago) in adjacent areas now affected by BEN (fig. 5). 


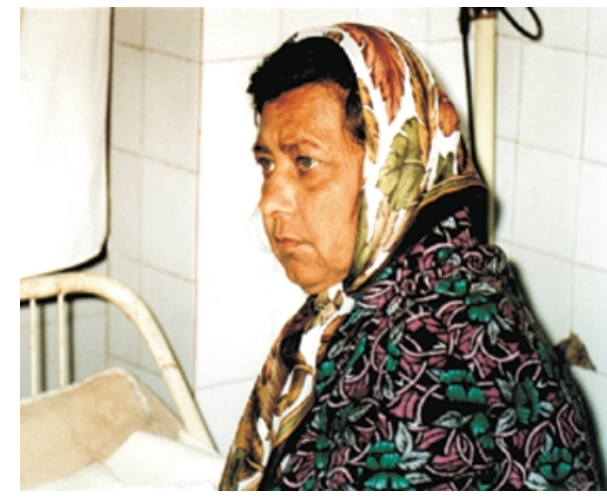

Figure 4. Patient with BEN in a renal dialysis unit in Romania. Usually BEN patients do not exhibit external signs of the disease, except for a dark-yellow tint of the skin (xantochromia)

Figure 6 shows gas chromatograms of organic compounds extracted in the laboratory by water from three samples: a Pliocene lignite from the main BENaffected region of Romania, a Pliocene lignite from an affected area of Serbia, and a bituminous coal from the eastern United States. Note the much richer yield of peaks for organic compounds in the chromatograms from the Pliocene lignites compared to the chromatogram from the bituminous coal.

\section{Geoscience and Medicine}

The study of BEN demonstrates the value of close working relations between the geoscience and medicine communities. The discrete and relatively small size of the affected regions, the stable population, and the welldescribed clinical aspects of BEN make it especially useful as a model for other diseases that may be linked to toxic organic substances from coal. For example, U.S. States having the highest incidence of upper urinary tract cancers also have extensive low-rank coal deposits (lignites) and predominantly rural populations. Geomedical research is needed to study whether these cancers are caused by toxic organic compounds leached from coal.

Coal deposits are present worldwide, and several direct links between coal combustion and disease in humans have been documented (Finkelman, 2000). Studies of BEN indicate that contamination resulting directly from coal deposits could also affect human health in susceptible population groups.

\section{Medical Aspects of BEN}

$\mathrm{BEN}$ is a disease of the kidneys culminating in end-stage renal failure, the complete shutdown of kidney function (for a review, see Tatu and others, 1998). BEN patients must either undergo regular dialysis treatment or have a kidney transplant. Without dialysis or a transplant, BEN patients die from uremia, the buildup of poisonous waste products in the bloodstream causing major organ failure. Most BEN patients live in rural villages and must be transported every 2-3 days by ambulance to a dialysis clinic for treatment lasting 2-3 hours. Figure 4 shows a patient with BEN in the dialysis clinic in Drobeta Turnu Severin, the major town in the main BEN-affected area of Romania.

The pathology of BEN is that of a tubulo-interstitial nephropathy, wherein the proximal tubules of the kidneys that are involved in separating waste material from the blood are damaged and cease to function. The kidneys of BEN patients are shrunken to one-third of their normal size. In many of its clinical aspects, BEN resembles analgesic nephropathy, a kidney disease resulting from long-term use of phenacetin and acetaminophen for pain relief. In contrast to most people who have kidney disease, only 20 percent of the BEN patients suffer from high blood pressure. The absence of high blood pressure is an unusual and currently unexplained aspect of the disease.

Another interesting medical aspect of the disease is the high occurrence of cancers of the upper urinary tract in patients with BEN. These cancers are rare in the general population but occur with a frequency of about 40-50 percent in BEN patients. This coincidence suggests that the toxin(s) responsible for the kidney disease in BEN may also be causing the high incidence of upper urinary tract cancers or that different toxin(s) from the same source (Pliocene lignites) may be responsible for BEN and the cancers.

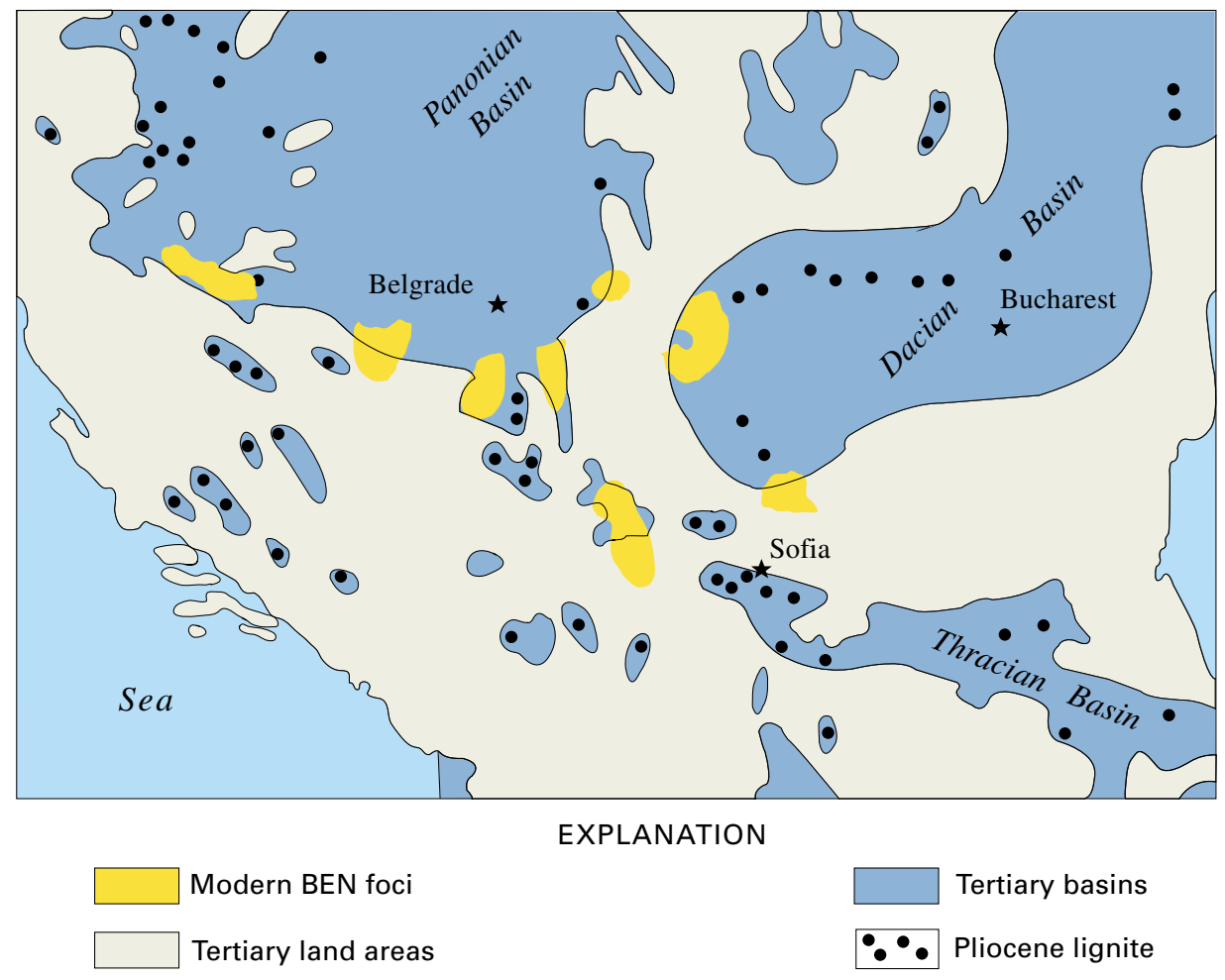

Figure 5. Map of the Balkan Peninsula showing basins that existed during the Tertiary (66.4 million-1.6 million years ago); modified from Jasko (1973). Modern BEN-affected areas (yellow here and in fig. 1) coincide with the margins of Tertiary basins. Subtropical vegetation formed peat deposits in shallow, swampy waters along the basin margins; subsequent burial and heating of the peat created lignite. 


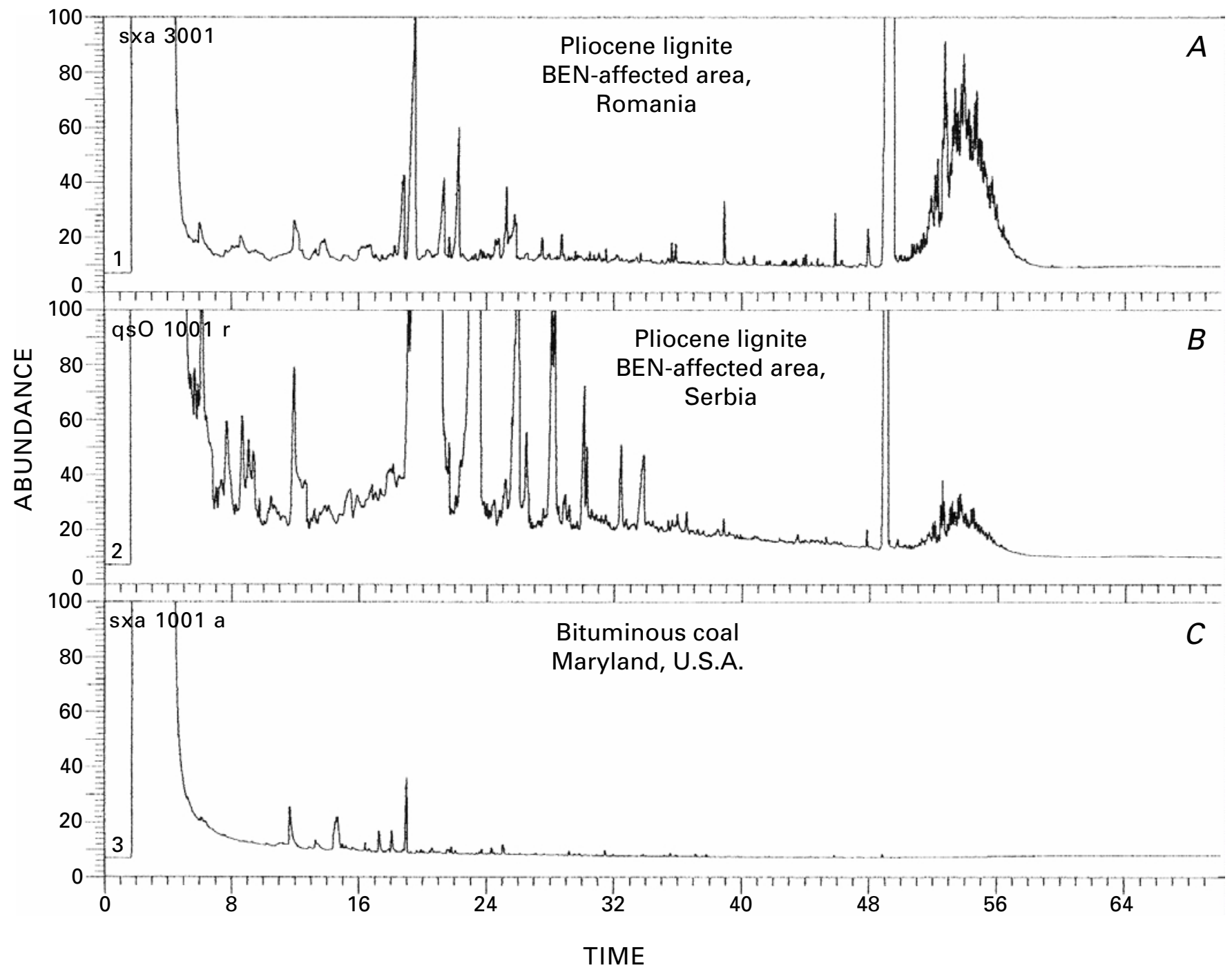

Figure 6. Gas chromatograms of laboratory water extracts of Pliocene lignites from two BEN-affected areas-Romania $(A)$ and Serbia $(B)$ and of a bituminous coal from Maryland, U.S.A. (C). Peaks indicate the presence of potentially toxic organic compounds.

\section{References}

Feder, G.L., Radovanovic, Z., and Finkelman, R.B., 1991, Relationship between weathered coal deposits and the etiology of Balkan endemic nephropathy: Kidney International, v. 40, supp. 34, p. S9-S11.

Finkelman, R.B., 2000, Health impacts of coal combustion: U.S. Geological Survey Fact Sheet FS-094-00, 2 p.

Hall, P.W., 1992, Balkan endemic nephropathy; More questions than answers: Nephron, v. 62 , no. 1 , p. 1-5.

Jasko, S., 1973, Lignitbildung im Pliozaen in Suedost-Europa [Lignite formation in the Pliocene of southeastern Europe]: Braunkohle, v. 25, p. 67-71.
Orem, W.H., Feder, G.L., and Finkelman, R.B., 1999, A possible link between Balkan endemic nephropathy and the leaching of toxic organic compounds from Pliocene lignites by groundwater: International Journal of Coal Geology, v. 40, no. 2-3, p. 237-252.

Tatu, C.A., Orem, W.H., Finkelman, R.B., and Feder, G.L., 1998, The etiology of Balkan endemic nephropathy; Still more questions than answers: Environmental Health Perspectives, v. 106, no. 11, p. 689-700.
For more information, please contact: William H. Orem

U.S. Geological Survey

National Center, Mail Stop 956

Reston, VA 20192

E-mail: borem@usgs.gov

Telephone: 703-648-6273

Fax: 703-648-6419

Calin A. Tatu

Institute of Public Health

Str. Vasile Goldis 1-3

Sc. 2 Et. 3 Ap. 10

RO-2900 Arad

Romania

E-mail: cta@med.unc.edu

Telephone: 40-92-607490 